Hamid Y, Svoboda P, Svobodova D. "Influence of Electron Beam Irradiation on High-Temperature Mechanical Properties of Ethylene Vinyl Acetate/Carbon Fibers Composites.". Journal of Vinyl \& Additive Technology: 11. Early Access: DEC 2019. https://doi.org/10.1002/vnl.21747

\title{
Influence of electron beam irradiation on high-temperature mechanical properties of ethylene vinyl acetate/carbon fibers composites
}

\author{
Yasin Hamida, Petr Svoboda ${ }^{a}$, Dagmar Svobodova ${ }^{b}$
}

\footnotetext{
a Department of Polymer Engineering, Faculty of Technology, Tomas Bata University in Zlin, Vavreckova 275, 76272 Zlin, Czech Republic

b Language Centre, Faculty of Humanities, Tomas Bata University in Zlin, Stefanikova 5670, 76001 Zlin, Czech Republic
}

Corresponding author. Tel. +420 576031331

E-mail address: hamid@utb.cz,

\begin{abstract}
:
The purpose of this study was to investigate the effect of carbon fiber (CF) and electron-beam (EB) radiation on high-temperature mechanical properties of ethylenevinyl acetate (EVA). Polymer composites were prepared by mixing on a two-roll mill. After compression molding, the samples were irradiated between 60 and $180 \mathrm{kGy}$, and dynamic mechanical analysis (DMA) was used to characterize physical properties. The effects of filler content and radiation level on the mechanical properties of EVA/CF were evaluated. The shear stress and modulus were observed to increase with increasing of the filler level. However, there was a dramatic decrease in creep compliance. It was also shown that introduction of irradiation on EVA composite increases the shear stress and the real part of the dynamic shear modulus G' due to the increase in molecular weight and cross-linking of the polymer after irradiation.
\end{abstract}

Keywords: ethylene-vinyl acetate, e-beam, DMA, carbon fiber 


\section{Introduction}

Carbon filled polymer composites have been popular due to their extensive utilization in various electronic equipment like temperature, pressure, dielectric, strain, gas, and biosensor materials.[1]

Carbon fibers (CF) have become an important reinforcing material in advanced composites because of their extremely high strength, stiffness, and heat-resistance, and low weight. Fiber-reinforced polymer composites are of great interest due to their very high strength-to-weight and stiffness-to-weight ratios. These properties are sought after in materials used in aerospace, engineering, marine industries, and automobile industries.[2]

The adhesion at the interface between matrix and fiber is an important issue in controlling the composite properties. An excellent interface between fiber and matrix can increase the stability and transfer the stress from matrix to fiber. However, chemical inertness and smooth surface of the fiber causes poor adhesion and lower enhancement in the properties of the composite.[3, 4]

E-beam radiation leads to cross-linking, to free radical formation and to chain scission, which cause a modification to the polymer structure. It was reported that e-beam radiation crosslinking could increase the electrical, mechanical and optical properties in the polymer [5].

It has also been observed that introducing carbon fiber or nanotube to EVA can improve the modulus and the tensile strength of the composite. Following, the mechanical properties and dynamic properties can be enhanced by entering the ebeam irradiation due to improving the filler to matrix interaction, which was shown in swelling resistance studies[6].

Polymer material radiation processing involves ionizing radiation of polymer treatment to enhance their chemical and mechanical properties. During the ionizing irradiation polymers can cross-link, be grafted or degrade.[7, 8] Mateev et al. investigated the effect of e-beam irradiation on gel formation process of EVA/PE films in range 40$250 \mathrm{kGy}$ when the major change in gel content occurred in range 40-170kGy [9]. This fact and our experience from our previous experiments [10] influenced our range of ebeam radiation, being this time 60,120 and $180 \mathrm{kGy}$. 
Electron beam (EB) irradiation on EVA/CF composite has been used in this study, and a variety of fiber concentration has been investigated. In this paper, the mechanical properties of EVA/CF composite under EB irradiation have been studied in detail. Testing of mechanical properties was done at room temperature $\left(25^{\circ} \mathrm{C}\right)$ and also at $150^{\circ} \mathrm{C}$. We are presenting only high-temperature results since they better reflect the influence of e-beam cross-linking.

At room temperature, the amorphous polymer chains are held together by crystal lamellae and by covenant bonds (from cross-linking). However, at $150^{\circ} \mathrm{C}$ only the chemical cross-linking holds the amorphous chain together.

\section{Experiment}

\section{Material}

Ethylene vinyl acetate with a trade name Supreme Ultra FL 00328 has been used. It was supplied by ExxonMobil Chemical Belgium (Antwerp Belgium) the melt flow index (MFI) is $3.0 \mathrm{~g} / 10 \mathrm{~min}$ and density is $0.951 \mathrm{~g} / \mathrm{cm}^{2}$; with $28 \mathrm{wt} \%$ of vinyl acetate. Carbon fiber was T700SC 12000-50C; it was provided by Torayca (Toray Carbon Fibers America) from Japan. It is a high strength, standard modulus fiber. This never twisted fiber is used in the high-tensile application. The specification of fiber is given in Table 1.

\section{Preparation of the composite}

EVA copolymer with carbon fiber was mixed and homogenized with various concentrations $\left(5,10,15,20,25 \mathrm{wt} \%\right.$ ) using two-roll mill at $150{ }^{\circ} \mathrm{C}$ for $5 \mathrm{~min}$. Following, a sheet with a thickness of $0.5 \mathrm{~mm}$ was prepared by compression molding at $10 \mathrm{MPa}$ with $5 \mathrm{~min}$ preheating at $150{ }^{\circ} \mathrm{C}$ and $5 \mathrm{~min}$ pressing; it was then placed into another cold press under pressure.

\section{Electron-beam irradiation}

Electron-beam irradiation was applied at room temperature in BGS Beta-GamaService Gmbh, Germany. The process was controlled not to surpass $50{ }^{\circ} \mathrm{C}$. The source of radiation was toroid electron accelerator Rhodotron (10 MeV, 200kW). The irradiation was applied in a tunnel on a moderately moving conveyor with the irradiation dosage ranging from 60 to $180 \mathrm{kGy}$ (30 kGy per pass) with $3 \mathrm{~m} / \mathrm{min}$ belt speed and $10 \mathrm{~mA}$ with $78 \mathrm{~cm}$ sample distance from the scanner for 2-second irradiation. 


\section{Dynamic mechanical analysis (DMA)}

The dynamic mechanical analysis was performed by METTLER Toledo Switzerland. Samples with dimensions of $11 \times 11 \times 0.5 \mathrm{~mm}$ were tested for creep-relaxation, stressstrain, and frequency sweep. The stress-strain was performed in a force range 0 to $2 \mathrm{~N}$ with $0.4 \mathrm{~N} / \mathrm{min}$ force rate at $150{ }^{\circ} \mathrm{C}$.

The creep relaxation was measured in three steps. At first, the sample was placed in DMA machine for $1 \mathrm{~min}$ at $150^{\circ} \mathrm{C}$ under $0.05 \mathrm{~N}$. Then, the sample was under creep test for $5 \mathrm{~min}$ at $150{ }^{\circ} \mathrm{C}$ under $1 \mathrm{~N}$ force. Finally, the force dropped to $0.05 \mathrm{~N}$ for $5 \mathrm{~min}$ at $150{ }^{\circ} \mathrm{C}$ for relaxation.

The frequency sweep test was done at $150{ }^{\circ} \mathrm{C}$ with a preload force of $0.1 \mathrm{~N}$ in the frequency range 0.1 to $100 \mathrm{~Hz}$ by 10 steps per decade with $10 \mu \mathrm{m}$ displacement.

\section{Gel content}

The gel contents of electron beam crosslinked EVA samples were obtained by a calculation of the insoluble crosslinked material after extracting the solvent according to

ASTM D2765-01. A small amount of crosslinked material (about $0.15 \mathrm{~g}$ ) was wrapped in a stainless steel cage and placed in boiling xylene solvent for $6 \mathrm{~h}$ with $1 \mathrm{wt} . \%$ of an antioxidant. The sample was weighted after evaporation of the solvent. Finally, the gel content was calculated as the percent ratio of the final weight to the initial weight of the

sample multiplied by one hundred.

\section{Optical microscopy}

Dimensions of carbon fibers were evaluated by optical microscopy using an Olympus RX41 microscope (Tokyo, Japan) to calculate the aspect ratio (L/D length over diameter) of carbon fibers in the composite.

\section{Size-exclusion chromatography}

The molecular weight measurement was performed at $160{ }^{\circ} \mathrm{C}$ on a Polymer Laboratories PL 220 high-temperature chromatograph (Polymer Laboratories, Varian Inc., Church Stretton, Shropshire, England) equipped with three $300 \mathrm{~mm} \times 7.5 \mathrm{~mm}$ PLgel Olexis columns and a differential refractive index detector. 1,2,4trichlorobenzene (TCB) was used as an eluent, stabilized with butylhydroxytoluene 
(BHT) (Ciba, Basel, Switzerland) as an antioxidant. A mobile phase flow rate of $1 \mathrm{~mL}$ $\min ^{-1}$ was used, and the volume $200 \mu \mathrm{L}$ was injected. Sample was prepared to a concentration of $0.5 \mathrm{mg} \mathrm{mL}^{-1}$ in TCB. Narrowly distributed polyethylene standards (Polymer Standards Service $\mathrm{GmbH}$, Mainz, Germany) were used for calibration purposes.

\section{Results and discussion}

The influence of carbon fibers and radiation on shear stress, on creep compliance and on frequency sweep of ethylene vinyl acetate (EVA) was investigated by dynamic mechanical analysis. The addition of carbon fiber into EVA leads to a significant increase in shear stress (see Fig. 1). This behavior is similar to the one reported by Das et al. [11].

The shear stress of the EVA composites with a content of $20 \mathrm{wt}$ \% of carbon fiber has the highest value, while the pure EVA has the lowest shear stress at the same shear strain (such as at 0.10 strain the values are about 0.004 and $0.007 \mathrm{MPa}$ for 0 and 20 wt.\% of CF, respectively), due to the improved interfacial action [12]. Hamid et al. reported that fiber could impart an extreme improvement in stiffness by hindering the movement within the matrix [13].

Increase of shear modulus as a function of increasing CF content is illustrated in Fig. 2. The highest values of G' were found for the sample irradiated by $180 \mathrm{kGy}$. These results are in agreement with other scientists. Increase in G' due to increasing volume fraction of carbon nanotubes was reported e.g. by Potschke et al. [14]. Increase in G' values at $0.1 \mathrm{rad} \mathrm{s}^{-1}$ due to increasing e-beam radiation for ethylene-octene copolymer was reported e.g. by Poongavalappil et al. [15].

To calculate the relative $G^{\prime}$ increase, it is necessary to calculate the volume fraction of the fiber in the composite.

Calculation of volume fraction $\left(\Phi_{A}\right)$ from weight fraction $w_{A}$

$$
w_{A}=\frac{m_{A}}{m_{A}+m_{B}} \quad E q .1
$$

Furthermore, since:

$$
V_{A}=\frac{m_{A}}{\varrho_{A}} \text { Eq. } 2
$$

So 


$$
\begin{aligned}
& \phi_{A}=\frac{V_{A}}{V_{A}+V_{B}}=\frac{\frac{m_{A}}{\varrho_{A}}}{\frac{m_{A}}{\varrho_{A}}+\frac{m_{B}}{\varrho_{B}}} \quad\left[. \frac{\frac{1}{m_{A}+m_{B}}}{\frac{1}{m_{A}+m_{B}}}\right. \\
& =\frac{\frac{m_{A}}{\varrho_{A} \cdot\left(m_{A}+m_{B}\right)}}{\frac{m_{A}}{\varrho_{A} \cdot\left(m_{A}+m_{B}\right)}+\frac{m_{A}}{\varrho_{A} \cdot\left(m_{A}+m_{B}\right)}}=\frac{\frac{w_{A}}{\varrho_{A}}}{\frac{w_{A}}{\varrho_{A}}+\frac{w_{B}}{\varrho_{B}}} \quad \text { Eq.3 }
\end{aligned}
$$

while the densities of CF and EVA 328 are $1.80 \mathrm{~g} / \mathrm{cm}^{3}$ and $0.951 \mathrm{~g} / \mathrm{cm}^{3}$, respectively. The volume fraction is shown in Table 2.

There are several theoretical models to describe the molecular behavior of filled composites. The earliest theory was Einstein's hydrodynamic theory for viscosity of colloidal suspensions. Einstein model describes increase of viscosity due to the addition of spherical rigid particles. This model was modified for nonspherical particles, such as fibers. In case of fibers the length to diameter (L/D) aspect ratio f plays an important role. [16, 17]. Guth and Gold generalized the Einstein's by replacing the viscosity with elastic modulus. However, different shape and size of fibers can lead to an unexplained and unpredictable modulus and formation of aggregates in the matrix. The modified equation of Guth and Smallwood [18]

Guth and Gold model is shown in Equation 4. The equation is designed for spherical particles [19].

Gm=unfilled modulus

$$
\frac{G c}{G m}=\left(1+2.5 \Phi+14.1 \Phi^{2}\right) \quad E q .4
$$

where: $\mathrm{Gc}=$ Shear modulus of the composite

$\mathrm{Gm}=$ shear modulus of the gum

$\Phi=$ volume fraction of the filler

Thus reinforcement factor $\frac{G c}{G m}$ is dependent only on the volume fraction of spherical filler in lower concentration. At higher concentration of the filler, it is observed that the reinforcement factor increases rapidly more than predicted by the equation. This is attributed to network formation or organization of filler particles into chain-like structures. To account for the "accelerated stiffening" caused by these chain- like or non-spherical fillers. Gugh-Smallwood shape factor $(f)$ for non-spherical particles and 
since the $f>1$, therefore the reinforcement factor will increase rapidly by increasing the fiber content.

$$
\frac{G c}{G m}=\left(1+0.67 f \Phi+1.62 f^{2} \Phi^{2}\right) E q .5
$$

Where: $f=$ shape factor

The volume fraction, density of each composite, experimental (see Fig.3), Guth - Gold for spherical and Guth-Smallwood for non-spherical particle are shown in Table 2.

In order to illustrate the modulus of EVA-CF composite, the aspect ratio of carbon fiber should be determined.

Fig.3 shows the comparison between the experimental modulus with Guth-Gold for spherical and Guth-Smallwood for non-spherical particles. It indicates that the nonspherical Guth-Smallwood is closer to the experimental data at lower concentrations, however at higher concentrations the Guth-Gold model is closer.

Correlation of experimental increase in modulus with theoretical predictive models was well illustrated e.g. by Mandal et al. [20].

The statistical data of the aspect ratio for EVA/CF composite are shown in Fig. $4 \mathrm{~b}$. This data were obtained from a variety of electronic microscope photographs of EVA in Fig.4a having different CF contents, i.e. 5-20wt\%.

The effect of irradiation dose on shear stress at 0.03 shear strain is visible in Fig. $5 \mathrm{~b}$. It is also common throughout the rubber industry to observe M100 modules and M300 of the modulus (at 100 and $300 \%$ elongation), and our choice was the stress at 0.03 shear strain. The graph indicates that EVA with a higher dose exhibited higher shear stress due to the fact that EVA with a higher dose contains more radiation cross-links compared to lower dose. It was observed that the shear stress of EVA with 5 wt.\% of carbon fiber was following an exponential rise with $\mathrm{R}^{2}=0.999$ regression. As demonstrated in Fig.5a, an addition of CF fiber with a higher radiation dose can enhance the shear stress, since CF as a filler and crosslinking can improve the stiffness by restricting the movement of the matrix [21, 22]. Improvements of physical and mechanical properties of electron beam irradiation crosslinked EVA foams was 
also reported by Rezaeian et al. [23]. Mechanical changes of electron-beam irradiated EVA film were reported by Matsui et al. [24].

The development of creep in time is shown in Fig.6a. The addition of carbon fiber to EVA causes reduction of the creep. It indicates that the addition of $20 \mathrm{wt} \%$ of CF caused almost three times lower creep compared to pure EVA. The graph also shows that not only the creep is decreasing with the addition of carbon fiber but also the rate of the creep (slope) decreases from 26 to 11 for pure EVA and 20 wt.\% of carbon fibers, respectively. Fig.6b suggests that there is a systematic decrease in creep with increasing content of the CF fibers after $5 \mathrm{~min}$ and also after recovery observed after $10 \mathrm{~min}$. Our results follow the trend of other researchers. Creep reduction due to the addition of nanofillers was reported e.g. by Shokrieh et al. [25].

Figs.6c,d show the sensitivity of creep to CF content and radiation dose. The graph (Fig. 6d) indicates that there is a significant decrease in creep with a radiation dose (kGy). It shows that EVA composite with a dose of $180 \mathrm{kGy}$ has nearly seven times lower creep in comparison with a dose of $60 \mathrm{kGy}$, which is caused by crosslinking. We have found an exponential decrease in creep compliance with increasing level of radiation in our previous study of ethylene-octene copolymer [26]. Creep reduction with increasing level of cross-linking (by the addition of peroxide) was also reported by Theravalappil et al. [27].

Fig.7 shows the tan $\delta$ vs. frequency, dose or CF content. The graph indicates that addition of fiber to EVA will increase the tan $\delta$. The tan $\delta$ for EVA composite (120 kGy) with $25 \%$ content of CF is nearly 0.4 , while the pure EVA is around 0.2 followed by 0.25 and 0.3 for $15 \%$ and $20 \%$, respectively. Decrease of tan $\delta$ value with increasing cross-linking level due to the addition of peroxide was reported e.g. by Poongavalappil et al. [28].

Tan $\delta$ values have dropped by raising the radiation level from $60 \mathrm{kGy}$ to $180 \mathrm{kGy}$. That is caused by an increase in molecular weight, which hinders the free flow of the material.

It is also evident that the tan $\delta$ of the composites decreases significantly with increasing of the frequency, as shown in Fig.7a and b., The influence of frequency on the tan $\delta$ is complex. The chain motion can be restricted with the change of the external force, and the internal friction is low at low frequency; so, the $\tan \delta$ is low [29]. While in our 
crosslinked EVA system the CF has caused increase in tan $\delta$ McNally et al. [30] reported a decrease in $\tan \delta$ values due to the addition of carbon nanotubes in an uncross-linked PE. Fig. 7c indicates the tan $\delta$ change with the dose at all frequencies. It shows that with increase of the dose, $\tan \delta$ is decreasing for all frequencies.

Fig. 8 shows the G' increases after irradiation. The increase of G' was observed in the irradiation dose ranging 60-180 kGy. For the EVA 25 wt.\% of carbon fiber, the increase of G' was higher. The highest increase of G' was found for EVA 25 wt.\% of carbon fiber (in the range 20-67 kPa). For the range of 60, 120 and $180 \mathrm{kGy}$ the G' values for pure EVA were 8, 17 and $28 \mathrm{KPa}$ respectively and for EVA 15 wt. $\%$ of carbon fiber they were 16, 23 and $43 \mathrm{kPa}$. Increase in G' due to the cross-linking was reported e.g. by Mussatti and Macosko [31].

It has been also observed that fiber has an increased influence at a higher frequency. Increase in G' value due to the increasing level of carbon nanotubes was reported e.g. by Potschke et al. [14, 32], and also due to the increasing level of graphene, e.g. by Kim and Macosko [33] or by Varghese et al. [34].

\section{Calculation of $\mathbf{G}$ parameters according to Charlesby-Pinner equation [10, 35]}

In order to be able to calculate Charlesby-Pinner parameters it is necessary to have data of molecular weight and data of gel content for various levels of irradiation.

Fig. 9 depicts the EVA molecular weight distribution using gel permeation chromatography (GPC). The graph shows that the molecular weight of EVA used in this study is between 300 to $5000000 \mathrm{~g} / \mathrm{mol}$. The peak position is around 100000 $\mathrm{g} / \mathrm{mol}$. The results from GPC test are listed in Table 3.

Fig.10 shows that increasing the radiation dose to $60 \mathrm{kGy}$ caused the generation of an insoluble 3D network with gel content being $72 \mathrm{wt} \%$. In the radiation range 60-180 kGy, the gel content is increasing only moderately as shown in Fig. 10 for $72 \%, 81 \%$ and $89 \%$ respectively, which could be ascribed to the increase in molecular weight 
and cross-linking. These results are in good agreement with Sharif et al. [36] who studied radiation effects on LDPE, EVA and their blends.

Fig. 10b was used in Charlesby-Pinner calculation as shown below.

\section{Calculation of the degree of polymerization}

EVA $328 \mathrm{MFI}=3$, Vinyl acetate $=28 \%$

$$
\begin{gathered}
\qquad \begin{array}{r}
\text { etylen }=-\mathrm{CH}_{2}-\mathrm{CH}_{2}-, \quad M_{E T}=2 \cdot \mathrm{C}+4 \cdot \mathrm{H}=2 \cdot 12.011+4 \cdot 1.008 \\
=28.054 \mathrm{~g} / \mathrm{mol}
\end{array} \\
\begin{array}{c}
\text { vinyl acetate }=-C H_{2}-\mathrm{CH}\left(\mathrm{O}-\mathrm{CO}-\mathrm{CH}_{3}\right)-, \quad M_{V A}=4 \cdot \mathrm{C}+2 \cdot \mathrm{O}+6 \cdot \mathrm{H} \\
=4 \cdot 12.011+2 \cdot 15.9994+6 \cdot 1.008=86.09 \mathrm{~g} / \mathrm{mol}
\end{array} \\
\text { wt. fraction of vinyl acetate } w_{V A}=\frac{28}{100}=0.28 \\
\text { wt.fraction of ethylene } w_{E T}=1-w_{V A}=1-0.28=0.72 \\
\text { molar fraction of vinyl acetate }=x_{V A} \\
\quad \frac{w_{V A}}{M_{V A}}=\frac{\frac{0.28}{86.09}}{\frac{w_{V A}}{M_{V A}}+\frac{w_{E T}}{M_{E T}}}=\frac{0.28}{86.09}+\frac{0.72}{28.054}
\end{gathered}
$$

molar fraction of ethylene $=x_{E T}=1-x_{V A}=1-0.1124717=0.8875283$

average molecular weight of repeating unit

$$
\begin{aligned}
M_{E T-O C T}= & x_{E T} M_{E T}+x_{V A} M_{V A}=0.8875 \cdot 28.054+0.1125 \cdot 86.09=34.58 \mathrm{~g} / \mathrm{mol} \\
& \text { Polymerization degree }=P_{n}=\frac{M_{n E V A}}{M_{E T-V A}}=\frac{43400}{34.58}=1255
\end{aligned}
$$

Charlesby-Pinner equation Error! Bookmark not defined.

$$
s+\sqrt{s}=\frac{p_{0}}{q_{0}}+\frac{1}{q_{0} P_{n} D} \text { Eq. } 6
$$

In plot $s+\sqrt{s}$ vs. $\frac{1}{D}: \quad$ intercept $=\frac{p_{0}}{q_{0}}, \quad$ slope $=\frac{1}{q_{0} P_{n}}$

In case of EVA-28: intercept $=0.3103$, slope $=39.38$

$$
\begin{gathered}
\text { then } \frac{p_{0}}{q_{0}}=0.3103 \text { and } \frac{1}{q_{0} P_{n}}=39.38 \\
q_{0}=\frac{1}{\text { slope } \cdot P_{n}}=\frac{1}{29.38 \cdot 1255}=0.000027121
\end{gathered}
$$

then $p_{0}=q_{0} \cdot$ intercept $=q_{0} \cdot \frac{p_{0}}{q_{0}}=0.000027121 \cdot 0.3103=0.0000084156$ 


$$
\begin{gathered}
s+\sqrt{s}=\frac{G(S)}{2 G(X)}+\frac{4.82 \times 10^{6}}{G(X) M_{n} D} \text { Eq.7 } \\
\text { then } \frac{G(S)}{2 G(X)}=\frac{p_{0}}{q_{0}} \\
\frac{G(X)}{G(S)}=\frac{1}{2 \frac{p_{0}}{q_{0}}}=\frac{1}{2 \cdot 0.3103}=1.6113 \\
\text { slope }=\frac{4.82 \times 10^{6}}{G(X) M_{n}} \\
G(X)=\frac{4.82 \times 10^{6}}{\text { slope } \cdot M_{n}}=\frac{4.82 \times 10^{6}}{29.3832 \cdot 43400}=3.7797 \\
\text { in tercept }=\frac{G(S)}{2 G(X)} \text { Eq.8 } \\
G(S)=2 \cdot G(X) \cdot \text { intercept }=2 \cdot 3.7797 \cdot 0.3103=2.3456
\end{gathered}
$$

All the important parameters are listed in Table 4. Parameters $G(X)=3.78$ and $G(S)=2.35$ mean that both cross-linking and chain scission occur during e-beam irradiation. The ratio of the parameters $G(X) / G(S)=1.61$ indicates that cross-linking prevails over the scission for this copolymer. The ratio $G(X) / G(S)=1.61$ is comparable to our previous results on ethylene-octene copolymer with $30 \mathrm{wt}$ \% of octene [37] when the ratio was 1.77 .

\section{Conclusion}

Ethylene vinyl acetate combined with carbon fiber was prepared, and the mechanical properties and irradiation effect at $150^{\circ} \mathrm{C}$ were studied. The EVA-CF composites were found to have higher shear modulus for given shear strain by adding of filler and with increasing irradiation, which was due to the interaction between the matrix and fiber and by increasing of the molecular weight with irradiation due to crosslinking. It was also observed that tan $\delta$ decreased with increasing of the dose from 60 to $180 \mathrm{kGy}$ for 0.1 to $100 \mathrm{~Hz}$ frequencies. There was a dramatic decrease in creep with increasing CF content and increasing irradiation, which confirmed the high interaction and raised cross-linking level. The analysis of unsolvable gel content confirmed the effect of 
irradiation on cross-linking since application of the radiation dose up to $180 \mathrm{kGy}$ increased the amount of insoluble gel.

\section{Appendix}

The densities of the composites were calculated according to these equations:

$$
\begin{gathered}
V_{A}+V_{B}=V_{\text {comp }} \\
\rho=\frac{m}{V}, \quad V=\frac{m}{\rho} \\
\frac{m_{A}}{\rho_{A}}+\frac{m_{B}}{\rho_{B}}=\frac{m_{c o m p}}{\rho_{\text {comp }}} \\
w_{A}=\frac{m_{A}}{m_{c o m p}}, \quad w_{B}=\frac{m_{B}}{m_{\text {comp }}}, w_{A}+w_{B}=1 \\
\frac{m_{A}}{\rho_{A}}+\frac{m_{B}}{\rho_{B}}=\frac{m_{\text {comp }}}{\rho_{\text {comp }}} \cdot\left[\frac{1}{\frac{m_{c o m p}}{m_{\text {comp }}}}\right. \\
\frac{w_{A}}{\rho_{A}}+\frac{w_{B}}{\rho_{B}}=\frac{1}{\rho_{c o m p}} \\
\rho_{c o m p}=\frac{1}{\frac{w_{A}}{\rho_{A}}+\frac{w_{B}}{\rho_{B}}}
\end{gathered}
$$

Densities of the composites are listed in Table 2. These values are in a good agreement (within $\pm 3 \%$ ) to the experimentally obtained values (by pycnometer).

\section{Acknowledgement}

This work has been supported by the Internal Grant Agency (IGA/FT/2017/007) of the Tomas Bata University in Zlin.

\section{References:}

[1] Mohd Radzuan NA, Yusuf Zakaria M, Sulong AB, Sahari J. The effect of milled carbon fibre filler on electrical conductivity in highly conductive polymer composites. Composites Part B: Engineering. 2017;110:153-160.

[2] Jin FL, Lee SY, Park SJ. Polymer matrices for carbon fiber-reinforced polymer composites. Carbon Lett. 2013;14(2):76-88.

[3] Tiwari S, Bijwe J, Panier S. Gamma radiation treatment of carbon fabric to improve the fiber-matrix adhesion and tribo-performance of composites. Wear. 2011;271(910):2184-2192. 
[4] Li J, Sun F. The effect of nitric acid oxidization treatment on the interface of carbon fiberreinforced thermoplastic polystyrene composite. Polymer-Plastics Technology and Engineering. 2009;48(7):711-715.

[5] Raj JM, Ranganathaiah C. A New Method of Stabilization and Characterization of the Interface in Binary Polymer Blends by Irradiation: A Positron Annihilation Study. J Polym Sci Pol Phys. 2009;47(6):619-632.

[6] George JJ, Bhowmick AK. Fabrication and Properties of Ethylene Vinyl Acetate-Carbon Nanofiber Nanocomposites. Nanoscale Res Lett. 2008;3(12):508-515.

[7] Makuuchi K, Cheng S. Radiation processing of polymer materials and its industrial applications: John Wiley \& Sons; 2012.

[8] Ramarad S, Ratnam CT, Khalid M, Chuah AL, Hanson S. Improved crystallinity and dynamic mechanical properties of reclaimed waste tire rubber/EVA blends under the influence of electron beam irradiation. Radiat Phys Chem. 2017;130:362-370.

[9] Mateev M, Karageorgiev S. The effect of electron beam irradiation and content of EVA upon the gel-forming processes in LDPE-EVA films. Radiat Phys Chem. 1998;51(2):205206.

[10] Svoboda P. Influence of Branching Density in Ethylene-Octene Copolymers on Electron Beam Crosslinkability. Polymers-Basel. 2015;7(12):2522-2534.

[11] Das A, Stockelhuber KW, Jurk R, Saphiannikova M, Fritzsche J, Lorenz H, et al. Modified and unmodified multiwalled carbon nanotubes in high performance solution-styrenebutadiene and butadiene rubber blends. Polymer. 2008;49(24):5276-5283.

[12] Yu KJ, Wang ML, Wu JQ, Qian K, Sun J, Lu XF. Modification of the Interfacial Interaction between Carbon Fiber and Epoxy with Carbon Hybrid Materials. Nanomaterials-Basel. 2016;6(5).

[13] Hamid Y, Abu Bakar A, Deirram N. Mechanical and Morphological Properties of Waste Eurycoma longifolia Fiber/Montmorillonite Reinforced Poly(vinyl chloride) Hybrid Composites. J Appl Polym Sci. 2013;128(2):1170-1175.

[14] Potschke P, Fornes TD, Paul DR. Rheological behavior of multiwalled carbon nanotube/polycarbonate composites. Polymer. 2002;43(11):3247-3255.

[15] Poongavalappil S, Svoboda P, Theravalappil R, Svobodova D, Danek M, Zatloukal M. Study on the influence of electron beam irradiation on the thermal, mechanical, and rheological properties of ethylene-octene copolymer with high comonomer content. J Appl Polym Sci. 2013;128(5):3026-3033.

[16] Qian JW, Wang M, Han DL, Cheng RS. A novel method for estimating unperturbed dimension [eta](theta) of polymer from the measurement of its [eta] in a non-theta solvent. Eur Polym J. 2001;37(7):1403-1407.

[17] Jayanarayanan K, Thomas S, Joseph K. Effect of blend ratio on the dynamic mechanical and thermal degradation behavior of polymer-polymer composites from low density polyethylene and polyethylene terephthalate. Iran Polym J. 2016;25(4):373-384.

[18] Jha V, Hon AA, Thomas AG, Busfield JJC. Modeling of the effect of rigid fillers on the stiffness of rubbers. J Appl Polym Sci. 2008;107(4):2572-2577.

[19] Rezende CA, Braganca FC, Doi TR, Lee LT, Galembeck F, Boue F. Natural rubber-clay nanocomposites: Mechanical and structural properties. Polymer. 2010;51(16):36443652.

[20] Mandal S, Alam S. Studies on the mechanical, thermal, and morphological properties of poly(ether ether ketone)/poly(ether sulfone)/barium titanate nanocomposites: 
Correlation of experimental results with theoretical predictive models. J Appl Polym Sci. 2012;126(2):724-733.

[21] Oliani WL, Lima LFCP, Parra DF, Dias DB, Lugao AB. Study of the morphology, thermal and mechanical properties of irradiated isotactic polypropylene films. Radiat Phys Chem. 2010;79(3):325-328.

[22] Matthews KH, Stevens HNE, Auffret AD, Humphrey MJ, Eccleston GM. Gammairradiation of lyophilised wound healing wafers. Int J Pharm. 2006;313(1-2):78-86.

[23] Rezaeian I, Jafari SH, Zahedi P, Ghaffari M, Afradian S. Improvements of physical and mechanical properties of electron beam irradiation-crosslinked EVA foams. Polym Advan Technol. 2009;20(5):487-492.

[24] Matsui T, Shimoda M, Osajima Y. Mechanical Changes of Electron-Beam Irradiated Ethylene Vinyl-Acetate Copolymer (Eva) Film .1. Polym Int. 1992;29(2):85-90.

[25] Shokrieh Z, Shokrieh MM, Zhao Z. A modified micromechanical model to predict the creep modulus of polymeric nanocomposites. Polym Test. 2018;65:414-419.

[26] Svoboda P, Svobodova D, Mokrejs P, Vasek V, Jantanasakulwong K, Ougizawa T, et al. Electron beam crosslinking of ethylene-octene copolymers. Polymer. 2015;81:119-128.

[27] Theravalappil R, Svoboda P, Poongavalappil S, Svobodova D. Creep and Dynamic Mechanical Analysis Studies of Peroxide-Crosslinked Ethylene-Octene Copolymer. Macromol Mater Eng. 2012;297(8):761-767.

[28] Poongavalappil S, Svoboda P, Theravalappil R, Svobodova D, Vasek V, Jantanasakulwong $\mathrm{K}$, et al. Cross-linking kinetics study and high temperature mechanical properties of ethylene-octene copolymer (EOC)/dicumylperoxide(DCP) system. Eur Polym J. 2011;47(10):1949-1955.

[29] Liu MH, Li R, Wang G, Hou ZY, Huang B. Morphology and dynamic mechanical properties of long glass fiber-reinforced polyamide 6 composites. J Therm Anal Calorim. 2016;126(3):1281-1288.

[30] McNally T, Potschke P, Halley P, Murphy M, Martin D, Bell SEJ, et al. Polyethylene multiwalled carbon nanotube composites. Polymer. 2005;46(19):8222-8232.

[31] Mussatti FG, Macosko CW. Rheology of Network Forming Systems. Polym Eng Sci. 1973;13(3):236-240.

[32] Potschke P, Abdel-Goad M, Alig I, Dudkin S, Lellinger D. Rheological and dielectrical characterization of melt mixed polycarbonate-multiwalled carbon nanotube composites. Polymer. 2004;45(26):8863-8870.

[33] Kim H, Macosko CW. Processing-property relationships of polycarbonate/graphene composites. Polymer. 2009;50(15):3797-3809.

[34] Varghese AM, Rangaraj VM, Mun SC, Macosko CW, Mittal V. Effect of Graphene on Polypropylene/Maleic Anhydride-graft-Ethylene Vinyl Acetate (PP/EVA-g-MA) Blend: Mechanical, Thermal, Morphological, and Rheological Properties. Ind Eng Chem Res. 2018;57(23):7834-7845.

[35] Turgis JD, Coqueret X. Electron beam sensitivity of butyl acrylate copolymers: effects of composition on reactivity. Macromol Chem Physic. 1999;200(3):652-660.

[36] Sharif J, Aziz SHSA, Hashim K. Radiation effects on LDPE/EVA blends. Radiat Phys Chem. 2000;58(2):191-195.

[37] Svoboda P. High-temperature study of radiation cross-linked ethylene-octene copolymers. Polymer Bulletin. 2017;74(1):121-144. 


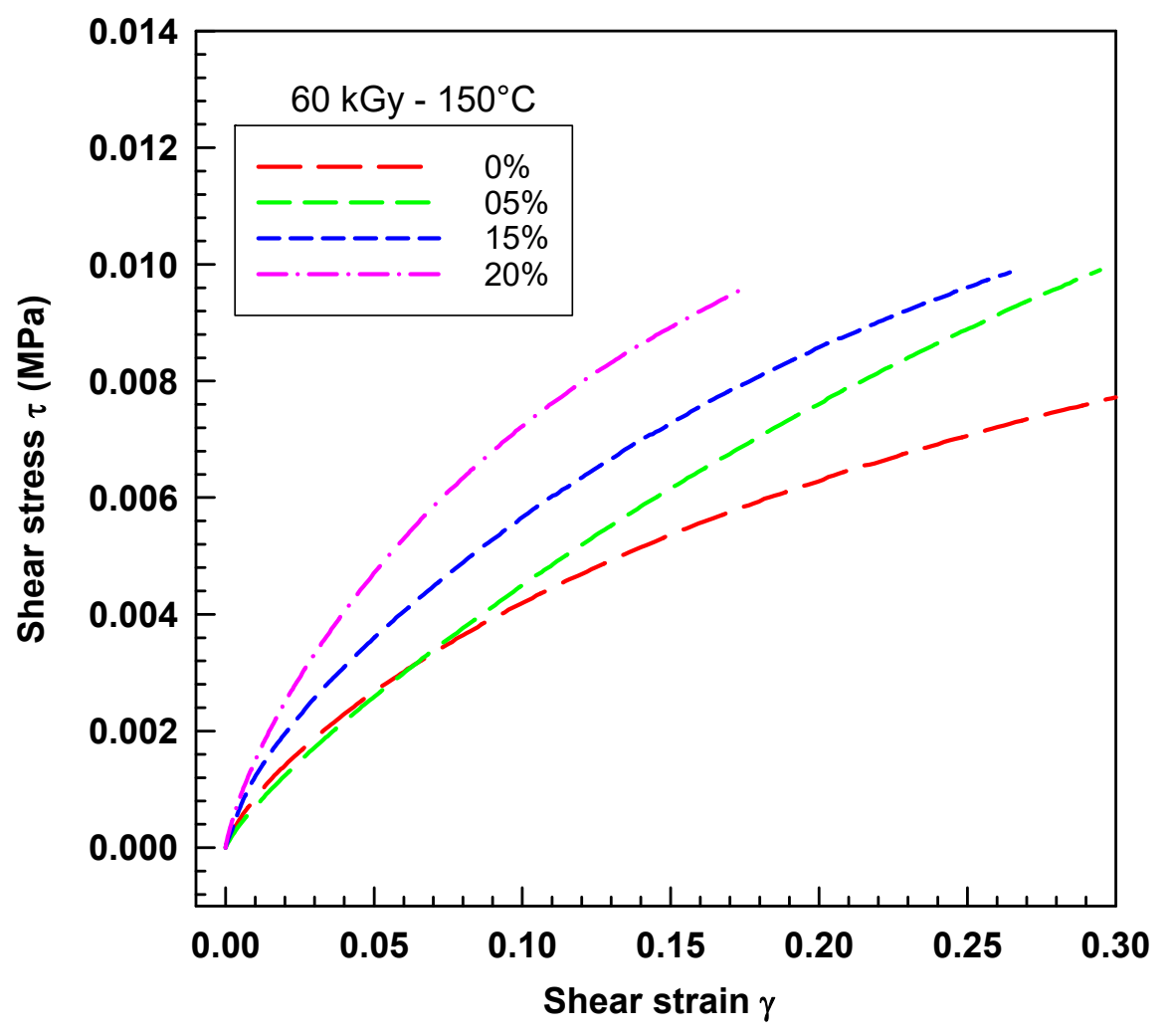

Fig. 1. Shear stress-strain curves of EVA/CF composites 


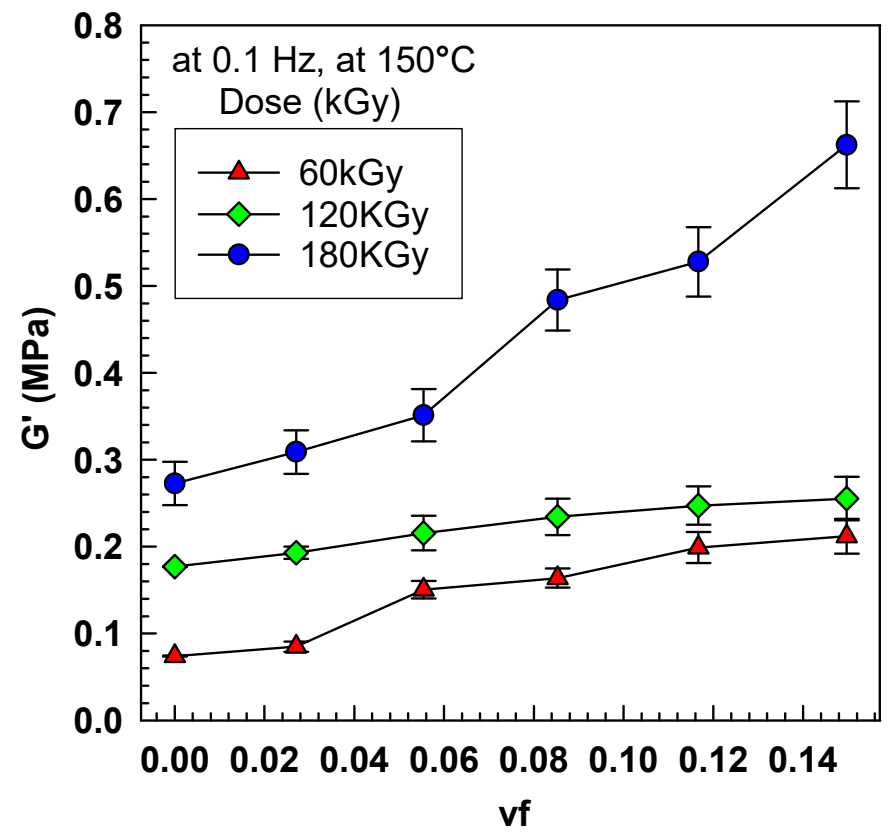

Fig.2. Experimental dynamic shear modulus (real part) G' at $150{ }^{\circ} \mathrm{C}$ at frequency 0.1 $\mathrm{rad} / \mathrm{s}$ 


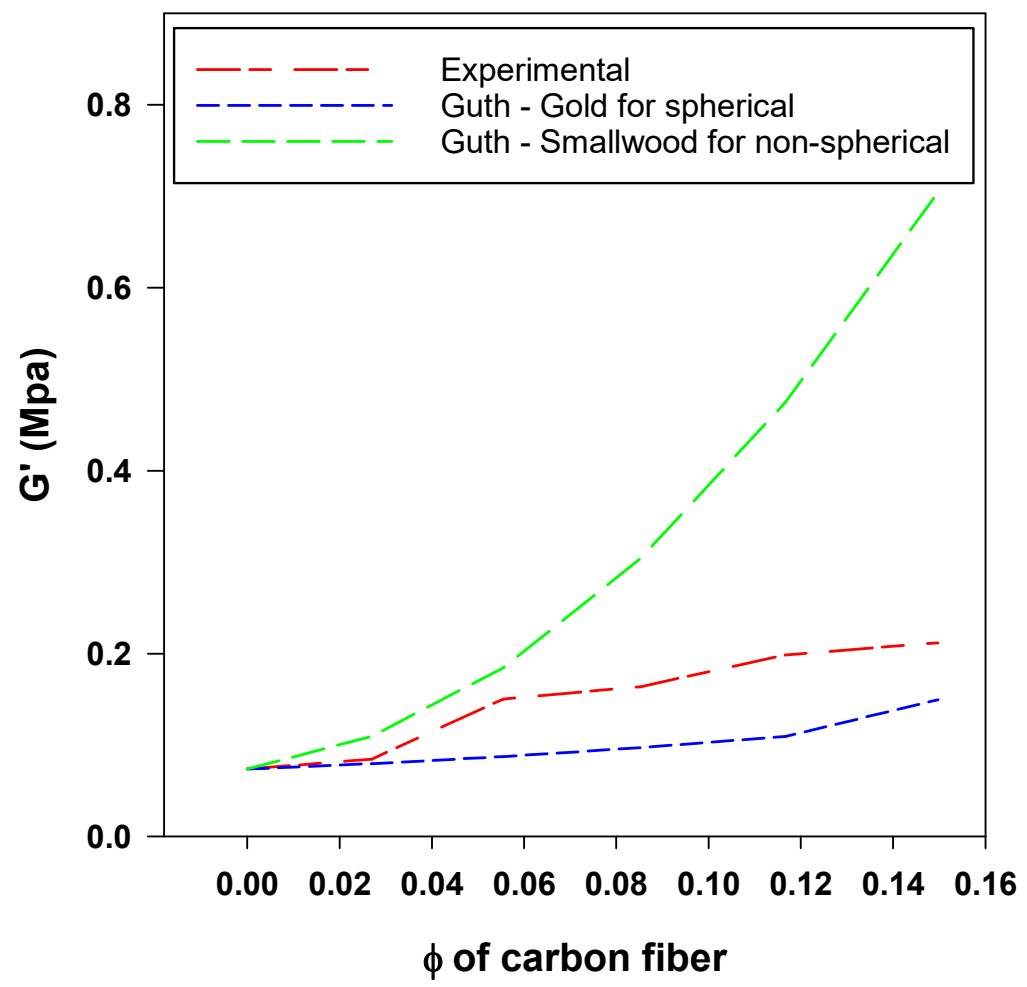

Fig. 3. Prediction of modulus with Guth - Gold for spherical and Guth - Smallwood for non-spherical filler vs. experimental data 

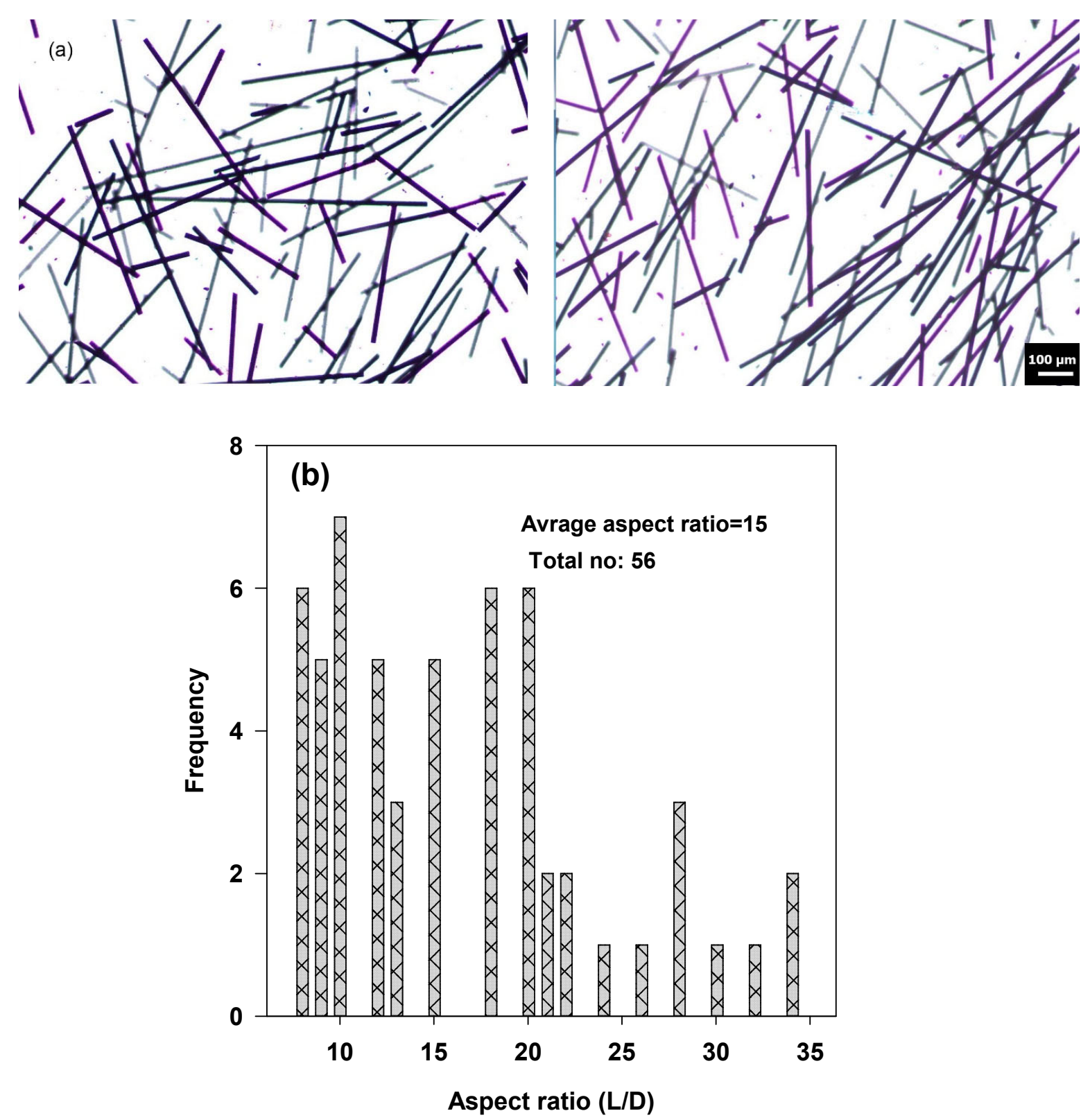

Fig. 4. a) Optical microscopy images of EVA/CF, b) histogram of the aspect ratio of carbon fibre in EVA/CF composites 

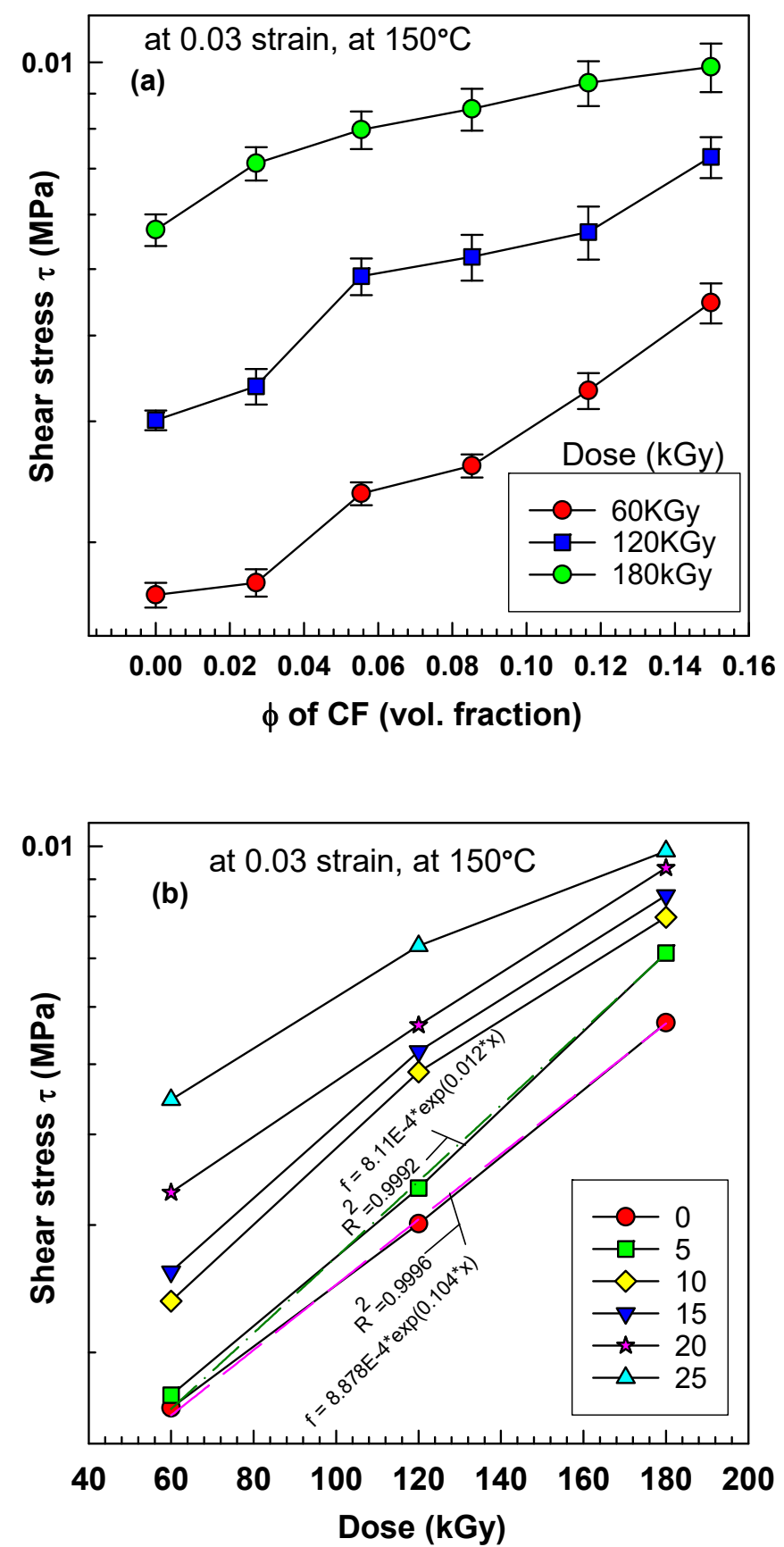

Fig. 5. a) Shear stress vs. vol. fraction of CF b) shear stress vs. dose for EVA/CF composites 

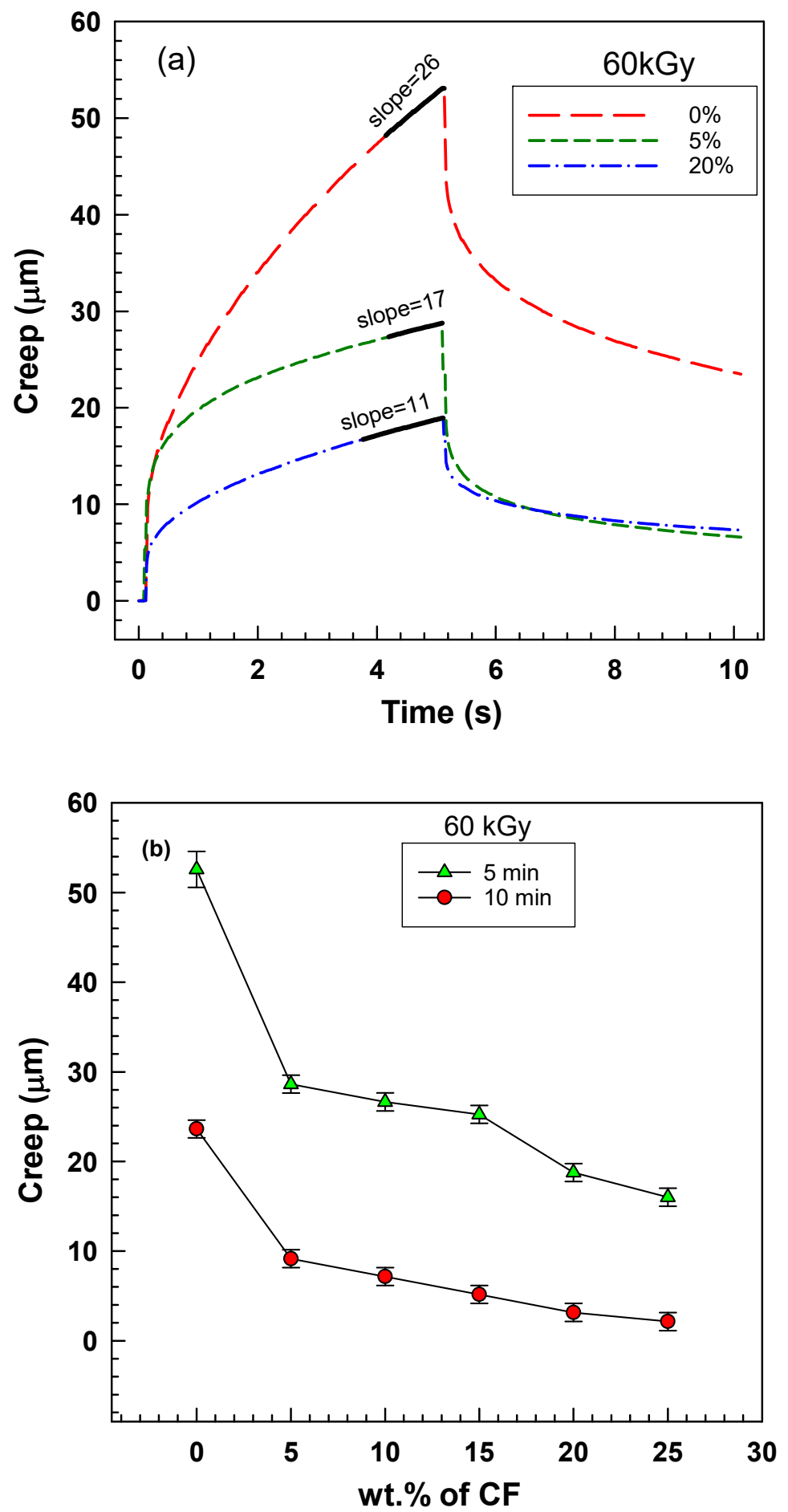

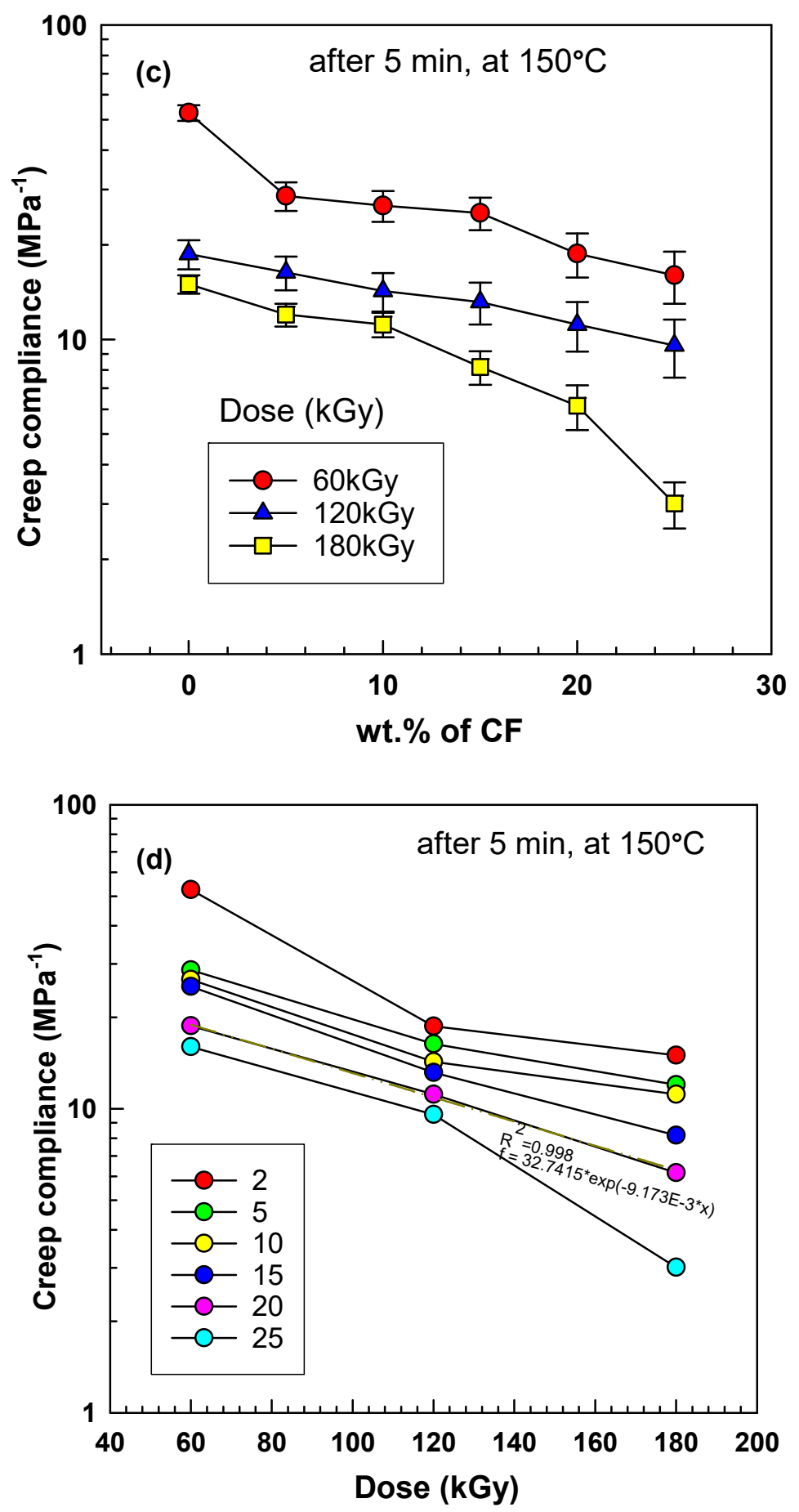

Fig.6. a) creep vs. time b) creep (recovery) vs. $\mathrm{CF}$ content at $150^{\circ} \mathrm{C}$, c) creep compliance vs. CF content for various doses, d) creep compliance vs. dose for various $\mathrm{CF}$ contents 

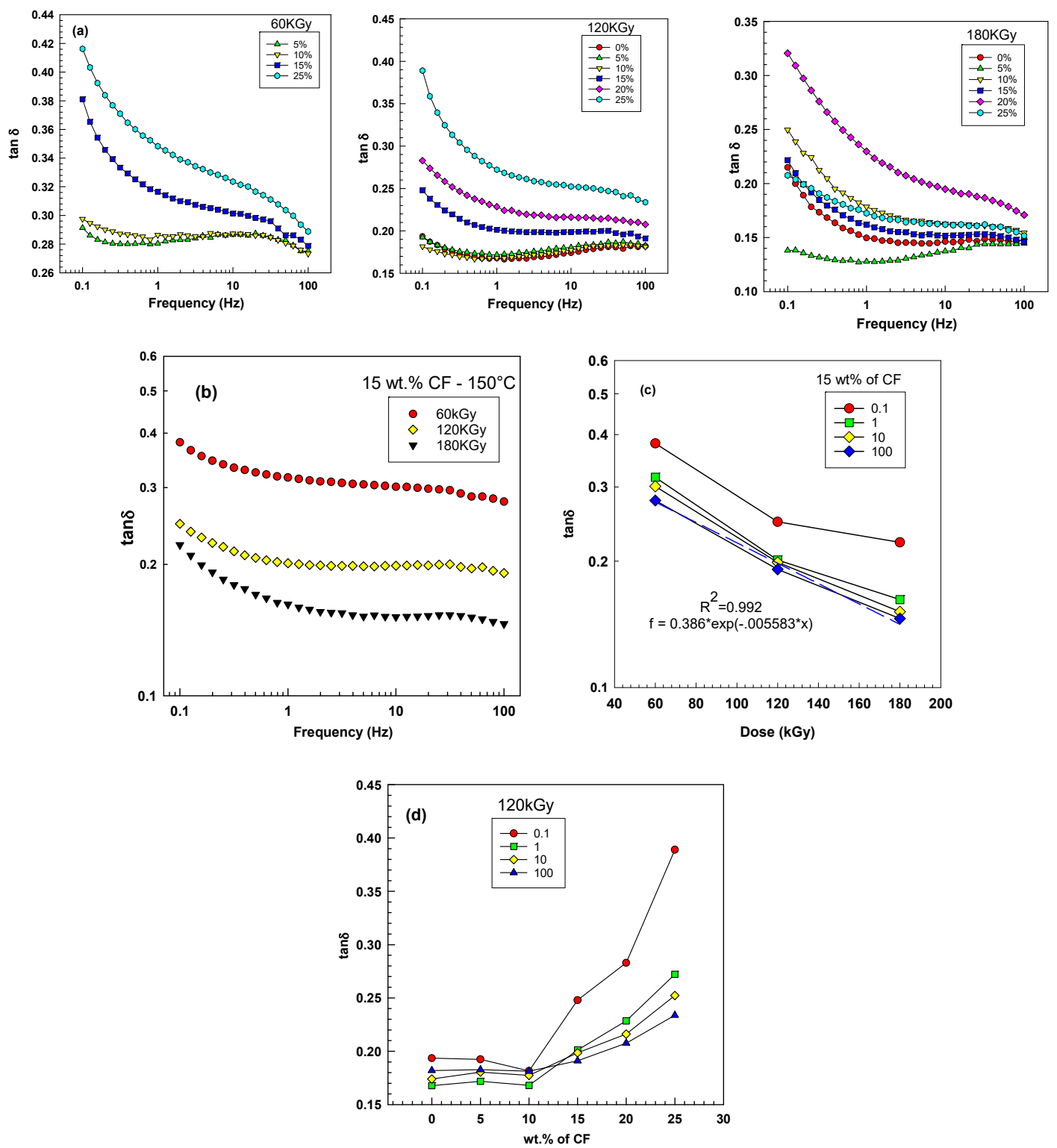

Fig. 7. $\tan \delta$ at $150^{\circ} \mathrm{C}$. a), b) as a function of frequency, c) as a function of dose at $0.1 \mathrm{rad} / \mathrm{s}, \mathrm{d}$ ) as a function of CF content 

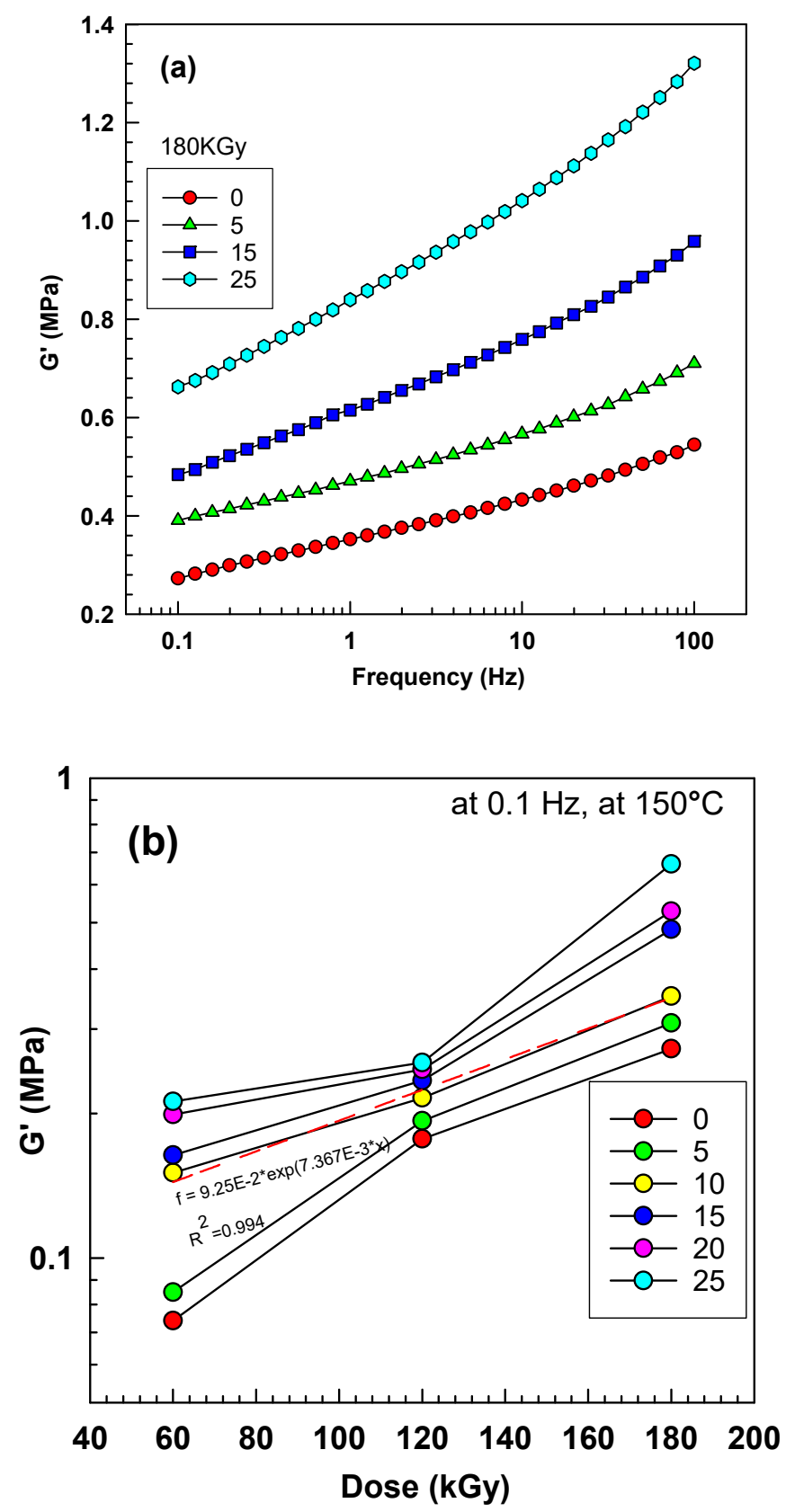

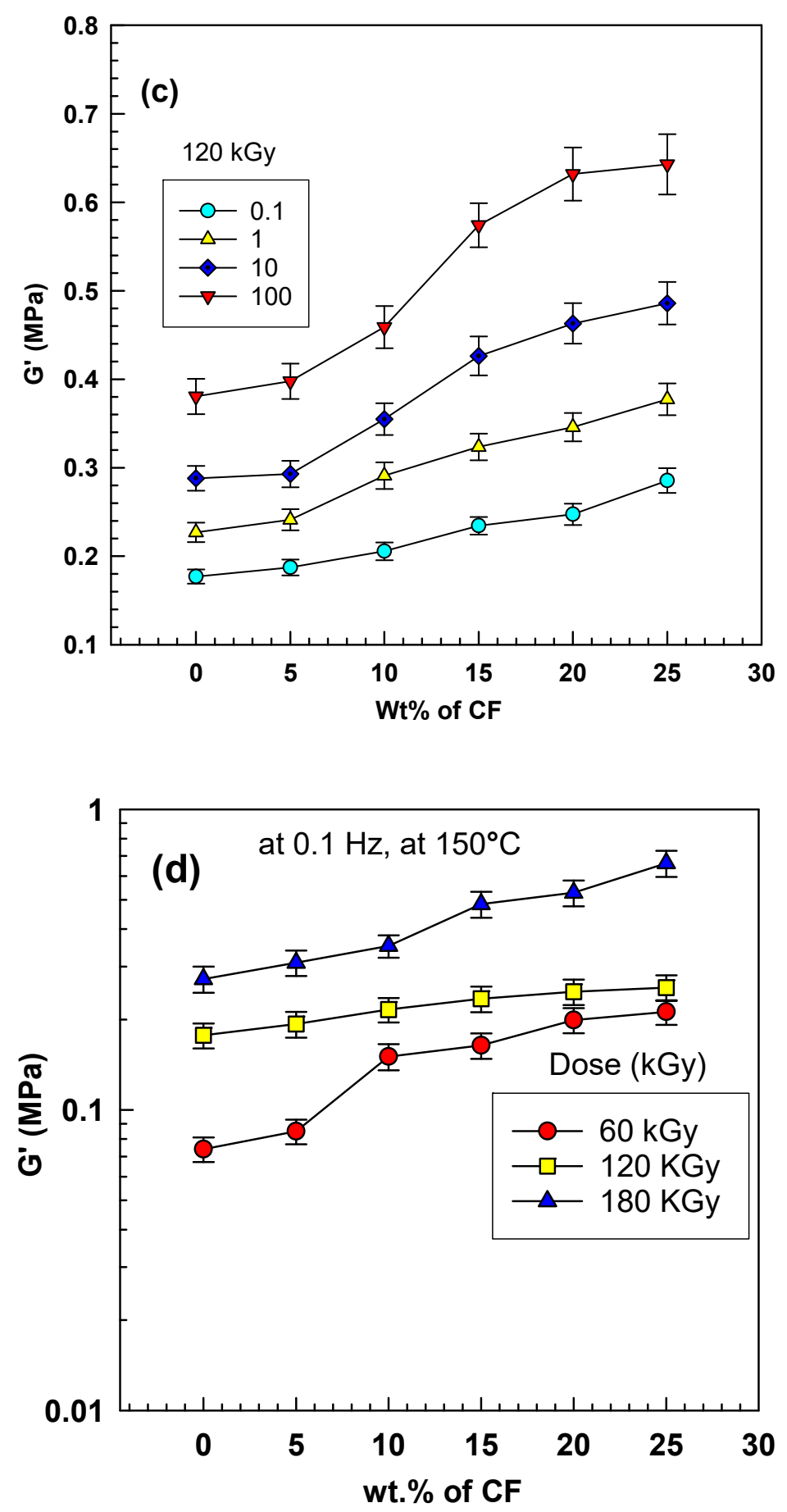

Fig. 8. Shear modulus (real part) $\mathrm{G}^{\prime}$ at $150^{\circ} \mathrm{C}$. a), b) as a function of frequency, c) as a function of $\mathrm{CF}$ content for various frequencies, d) as a function of $\mathrm{CF}$ content for various irradiation doses 


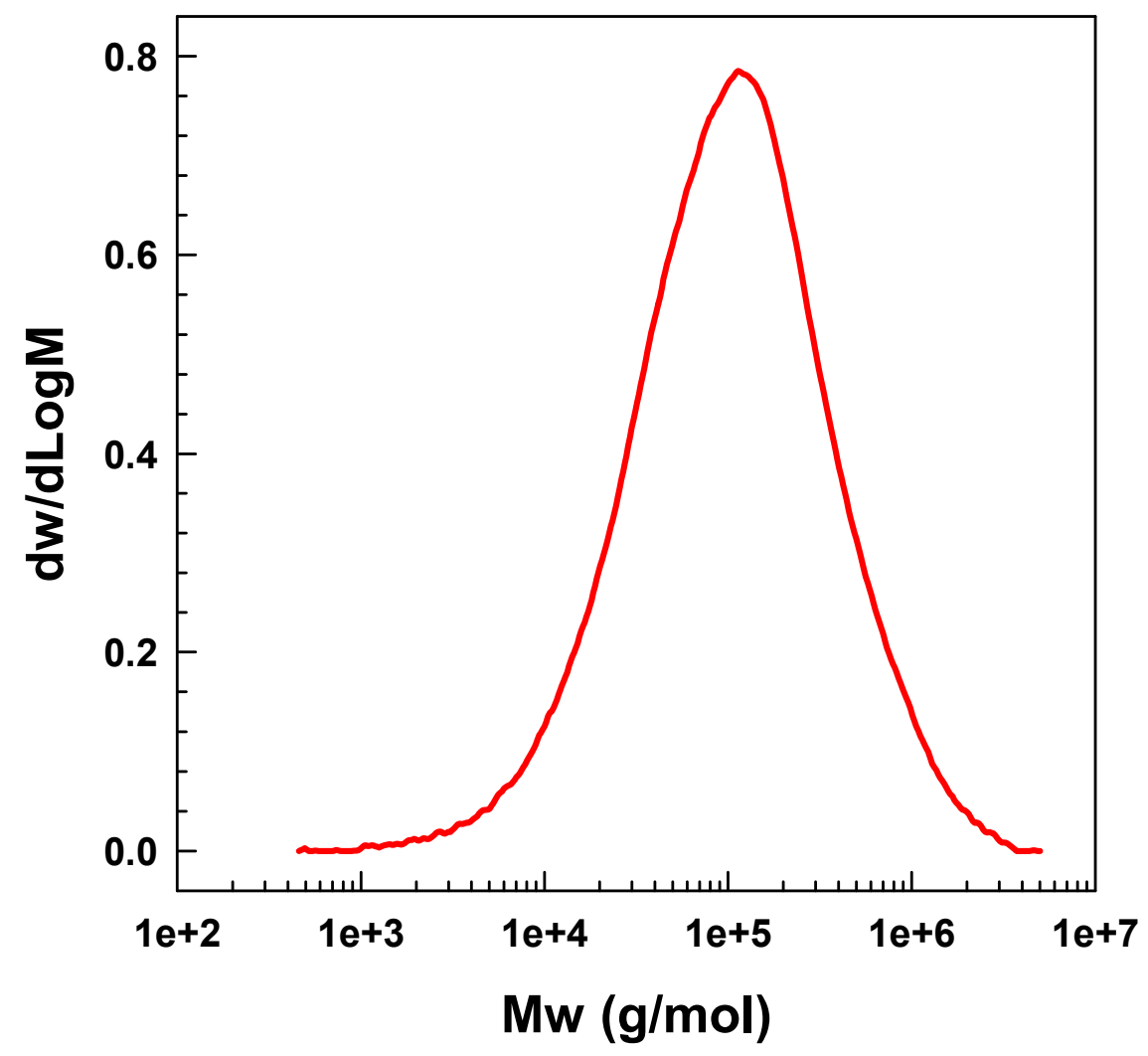

Fig.9. The molecular weight distribution of EVA 

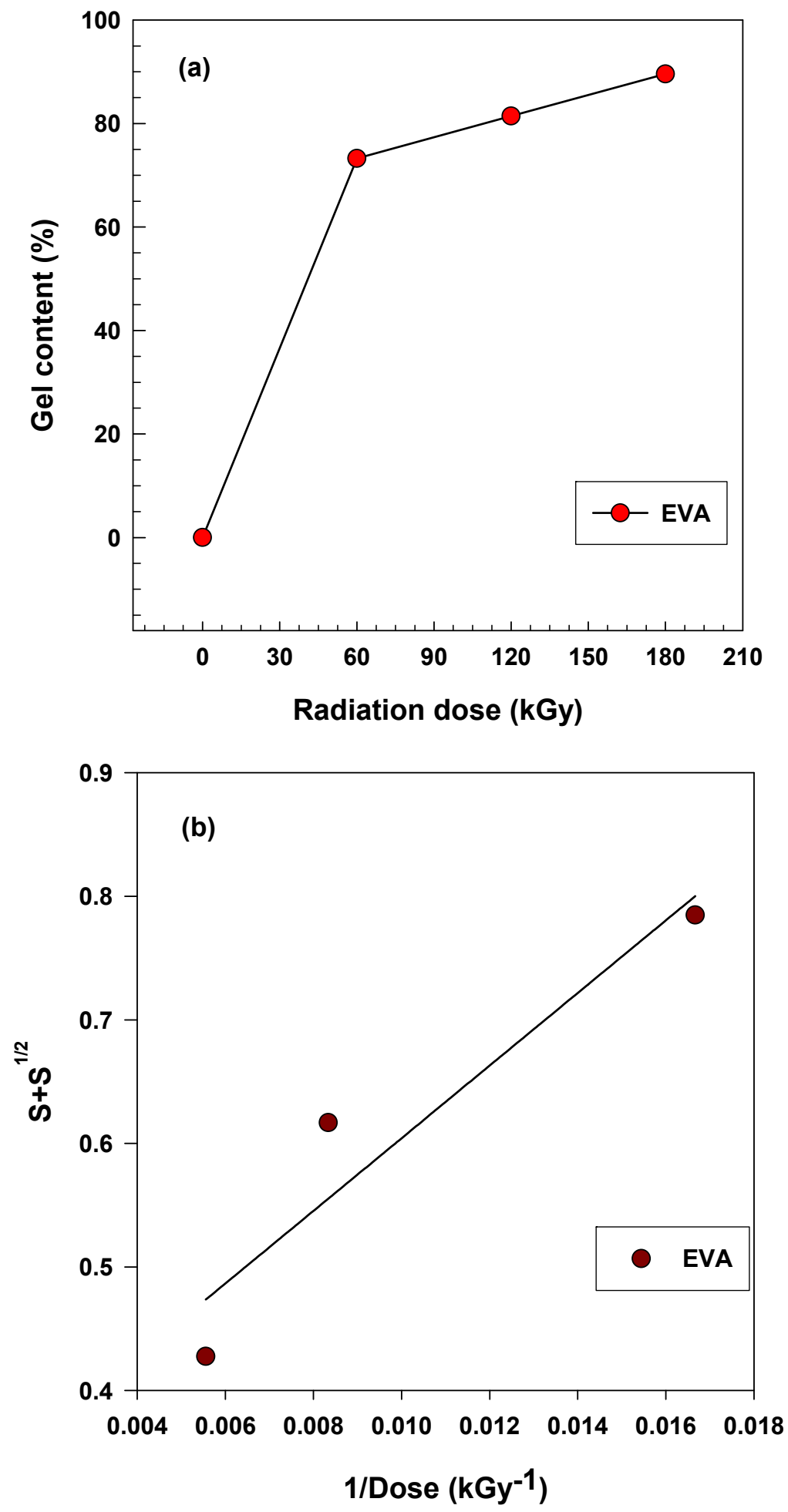

Fig. 10. a) Gel content vs. dose, b) Charlesby-Pinner analysis 
Table 1. Carbon fiber properties

\begin{tabular}{|c|c|}
\hline Tensile strength & $2,450 \mathrm{MPa}$ \\
\hline Tensile modulus & $125 \mathrm{GP}$ \\
\hline Strain & $2.1 \%$ \\
\hline Density & $1.8 \mathrm{~g} / \mathrm{cm}^{3}$ \\
\hline Filament diameter & $7 \mu \mathrm{m}$ \\
\hline
\end{tabular}


Table 2. Shear modulus for experimental data, Guth-Gold model for spherical particles and Guth-Smallwood model for non-spherical particles

\begin{tabular}{|c|c|c|c|c|c|}
\hline $\mathrm{Wa}$ & $\Phi \mathbf{a}$ & $\begin{array}{l}\text { Density } \\
\left(\mathrm{g} / \mathrm{cm}^{3}\right)\end{array}$ & $\begin{array}{c}\text { Experimental } \\
\text { at } 0.1 \mathrm{~Hz}\end{array}$ & $\begin{array}{c}\mathrm{G}=\mathrm{Gm}(1+ \\
\left.2.5 \Phi+14.1 \Phi^{2}\right)\end{array}$ & $\begin{array}{r}G c=G m(1+0.67 \\
\left.f \Phi+1.62 f^{2} \Phi^{2}\right)\end{array}$ \\
\hline 0 & 0 & 0.951 & 0.0740 & 0.0740 & 0.0740 \\
\hline 0.05 & 0.0270 & 0.974 & 0.0849 & 0.0797 & 0.1100 \\
\hline 0.10 & 0.0554 & 0.998 & 0.1505 & 0.0874 & 0.1847 \\
\hline 0.15 & 0.0852 & 1.023 & 0.1638 & 0.0973 & 0.3040 \\
\hline 0.20 & 0.1166 & 1.050 & 0.1990 & 0.1097 & 0.4748 \\
\hline 0.25 & 0.1497 & 1.078 & 0.2119 & 0.1497 & 0.7044 \\
\hline
\end{tabular}


Table 3. GPC results of EVA 328

\begin{tabular}{|l|l|l|l|l|l|r|}
\hline $\begin{array}{l}\text { Sample } \\
\text { Name }\end{array}$ & Mp & Mn & Mw & Mz & Mz+1 & PDI \\
\hline \multicolumn{7}{|c|}{$\mathrm{g} / \mathrm{mol}$} \\
\hline EVA 328 & 113000 & 43400 & 196000 & 625000 & 1286000 & 4.5 \\
\hline
\end{tabular}


Table 4. Results of the calculated Charlesby-Pinner parameters

\begin{tabular}{|c|c|c|c|c|c|c|c|}
\hline $\begin{array}{c}\text { wt.\% of } \\
\text { Vinyl } \\
\text { acetate }\end{array}$ & $\begin{array}{c}\text { wt. } \\
\text { fraction } \\
\text { of vinyl } \\
\text { acetate }\end{array}$ & $\begin{array}{c}\text { wt. } \\
\text { fraction } \\
\text { of } \\
\text { ethylene }\end{array}$ & $\begin{array}{c}\text { molar } \\
\text { fraction of } \\
\text { vinyl } \\
\text { acetate }\end{array}$ & $\begin{array}{c}\text { molar } \\
\text { fraction of } \\
\text { ethylene }\end{array}$ & $M_{E T-V A}$ & $M_{n}$ & $P_{n}$ \\
\hline 28 & 0.28 & 0.72 & 0.8875 & 0.1125 & 34.58 & 43400 & 1255 \\
\hline
\end{tabular}

\begin{tabular}{|c|c|c|c|c|c|c|}
\hline slope & $p_{0} / q_{0}$ & $q_{0}$ & $p_{0}$ & $G(X) / G(S)$ & $G(X)$ & $G(S)$ \\
\hline 29.38 & 0.3103 & $2.7121 \mathrm{E}-05$ & $8.4156 \mathrm{E}-06$ & 1.6113 & 3.7797 & 2.3456 \\
\hline
\end{tabular}

